\title{
Determinants of concentric left ventricular hypertrophy in patients with resistant hypertension: RESIST-POL study
}

\author{
Piotr Dobrowolski ${ }^{1,3}$, Aleksander Prejbisz ${ }^{2,3}$, Anna Klisiewicz ${ }^{1}$, Elżbieta Florczak², Justyna Rybicka ${ }^{1}$, \\ Andrzej Januszewicz ${ }^{2,4}$ and Piotr Hoffman ${ }^{1,4}$
}

Left ventricular hypertrophy, especially concentric hypertrophy, has been shown to be an independent factor of cardiovascular diseases in patients with hypertension. Obstructive sleep apnea (OSA) and/or metabolic syndrome (MS) are common in patients with resistant hypertension (RHTN). The aim of this study was to evaluate factors associated with concentric hypertrophy in patients with RHTN. Data from 155 patients (92M, 63F) was analyzed. All patients underwent a thorough examination including: biochemical evaluations, ambulatory blood pressure monitoring, polysomnography and echocardiography. MS was defined by The Adult Treatment Panel III. Clinically significant OSA was defined as apnea/hypopnea index (AHI) $>15$ events per hour. Left ventricular mass index (LVMI) and relative wall thickness (RWT) were calculated. Four types of LV geometry were distinguished based on the LVMI and RWT. Patients were divided into four groups based on the LV geometric patterns: group 1 (normal geometry) ( $n=38,24.4 \%)$; group 2 (concentric remodeling) $(n=40,25.8 \%)$; group 3 (eccentric hypertrophy) $(n=26$, $16.8 \%$ ); and group 4 (concentric hypertrophy) ( $n=51,33 \%$ ). MS was found in $64 \%$ and OSA (AHI $>15)$ in $43.2 \%$ of patients. Factors independently associated with concentric hypertrophy were: age (OR-1.51; 95\% Cl-1.00-2.27; $P<0.04)$, OSA $>15$ events per hour (OR-2.73; 95\% Cl-1.26-5.93; $P=0.01$ ) and nighttime systolic blood pressure (SBP) $(\mathrm{OR}-1.69 ; 95 \% \mathrm{Cl}-1.32$ 2.17; $P=0.0001)$. Concentric hypertrophy was the most common type of left ventricular disorder in patients with RHTN. Nighttime SBP and clinically significant OSA were independently associated with concentric hypertrophy in patients with RHTN. Hypertension Research (2015) 38, 545-550; doi:10.1038/hr.2015.39; published online 19 March 2015

Keywords: echocardiography; left ventricular concentric hypertrophy; metabolic syndrome; obstructive sleep apnea; resistant hypertension

\section{INTRODUCTION}

Left ventricular hypertrophy (LVH) is a known cardiovascular risk factor offering independent prognostic information, which is incremental to the clinical evaluation. ${ }^{1,2}$ The type of abnormal left ventricular geometry (LV) has also been associated with adverse outcomes. It has been demonstrated that patients with concentric hypertrophy have poorer outcomes than patients presenting normal LV geometry. ${ }^{3,4}$ Resistant hypertension (RHTN) is of major clinical importance since it is associated with higher cardiovascular risk $^{5-8}$ which can be dependent on concentric hypertrophy. However, RHTN often coexists with obstructive sleep apnea (OSA) $)^{9,10}$ and metabolic syndrome (MS), which also predispose to LVH. We systematically evaluated which clinical condition might be related to concentric hypertrophy in patients with RHTN.

\begin{abstract}
METHODS
Patients

Patients were enrolled in the Resist-POL study in the Department of Hypertension, Institute of Cardiology, Warsaw, Poland between 2009 and 2011. The population recruitment description is presented in Figure 1. The inclusion criteria were as follows: age 20-65, RHTN confirmed with $24-\mathrm{h}$ blood pressure monitoring (ambulatory blood pressure monitoring) - mean daytime BP >135/85 $\mathrm{mm} \mathrm{Hg}$ while on three antihypertensive drugs at optimal doses (including a diuretic agent). The exclusion criteria included a history of other cardiovascular diseases (ischemic heart disease, heart failure, transient ischemic attacks and previous stroke), decreased estimated glomerular filtration rate $<60 \mathrm{ml} \mathrm{min}^{-1}$ per $1.73 \mathrm{~m}^{2}$, previous diagnosis of diabetes mellitus, and others. ${ }^{11}$ None of the patients with RHTN enrolled in the study met the diagnostic criteria of hypertrophic cardiomyopathy. ${ }^{12}$ For this study we excluded 49 patients with secondary causes of hypertension which may independently influence the LV function. Primary hyperaldosteronism was diagnosed in 32 patients, renal artery stenosis in 11, Cushing's syndrome in two
\end{abstract}

\footnotetext{
${ }^{1}$ Department of Congenital Heart Diseases, Institute of Cardiology, Warsaw, Poland and ${ }^{2}$ Department of Hypertension, Institute of Cardiology, Warsaw, Poland

${ }^{3}$ These authors contributed equally to this work.

${ }^{4}$ They are equal senior authors.

Correspondence: Dr P Dobrowolski, Department of Congenital Heart Diseases, Institute of Cardiology, Alpejska 42, Warsaw 04-628, Poland.

E-mail p.dobrowolski@ikard.pl

Received 19 October 2014; revised 7 February 2015; accepted 20 February 2015; published online 19 March 2015
} 


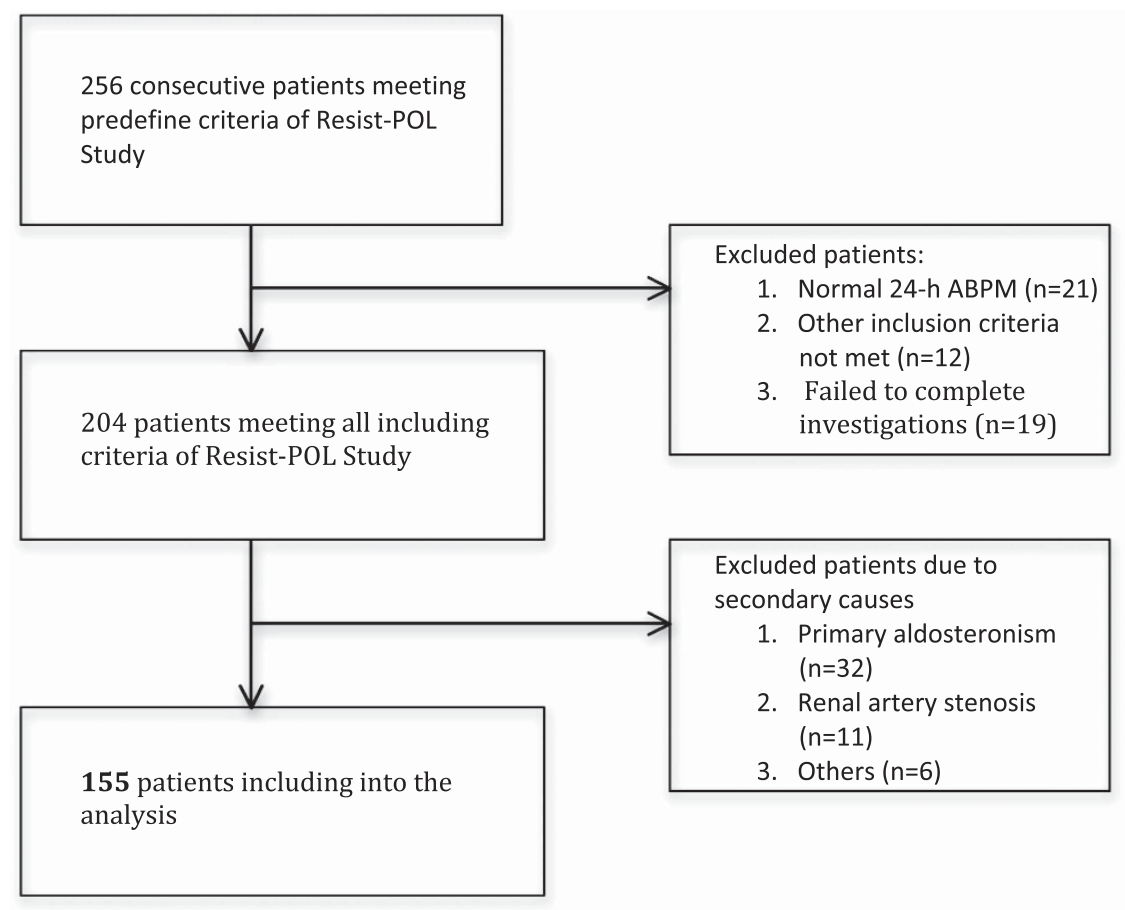

Figure 1 Protocol flowchart.

patients and other causes in four subjects. We emphasize that patients included in our analysis were characterized by newly diagnosed, never treated OSA and by being free of diabetes, severe cardiovascular disorders, chronic kidney disease and secondary causes of hypertension thus limiting the influence of other factors on cardiac structure and function. Written informed consent was obtained from each patient. The study protocol conforms to the ethical guidelines of the 1975 Declaration of Helsinki and was approved by the local Research Ethics Committee.

\section{Clinic and ambulatory blood pressure measurements}

BP was measured by a trained nurse by using an automated device (Omron 705IT, Omron, Kyoto, Japan) after a 5-min rest with the patient seated. Based on the upper arm circumference, an appropriately sized cuff was placed on the arm with the lower edge of the cuff $2 \mathrm{~cm}$ above the antecubital fossa and three consecutive readings were taken. In all patients the ambulatory BP measurements were recorded using SpaceLabs 90207 or 90217 (Redmond, WA, USA). Readings were obtained every $15 \mathrm{~min}$ during the day (6:00-22:00) and every $30 \mathrm{~min}$ during the night (22:00-6:00). The average 24-h, systolic blood pressure, diastolic blood pressure and average 24 -h heart rate were analyzed.

\section{Polysomnography}

The diagnosis of OSA was made by standard attended polysomnography by using an Alice 5 (Respironics, Murrysville, PA, USA) device. The recordings were scored manually in $30 \mathrm{~s}$ epochs following Rechtschaffen and Kales' criteria for sleep and wake determination and sleep staging. Abnormal respiratory events were evaluated according to the standard criteria of the American Academy of Sleep Medicine Task Force. ${ }^{13}$ The apnea/hypopnea index (AHI), indicating the number of apneic and hypopneic episodes per hour of sleep, was calculated. Clinically significant OSA was diagnosed when the AHI was above 15 events per hour.

\section{Echocardiography}

All patients underwent a complete transthoracic echocardiographic examination using a GE Medical System Vivid (GE Vingmed Ultrasound, Horten, Norway) 7 with a $2.5 \mathrm{MHz}$ transducer. M-mode, 2-D imaging were used. The values of all echocardiographic parameters were obtained from the average of three consecutive cardiac cycles. Left ventricular end-systolic (LVESd) and enddiastolic (LVEDd) diameters, as well as interventricular septal (IVSDd) and posterior wall thickness (PWDd) were measured according to the American Society of Echocardiography recommendations by using the M-mode technique. ${ }^{14}$ Left ventricular mass (LVM) was calculated using the formula proposed by Devereux. ${ }^{15}$ Left ventricular mass index (LVMI) was obtained by normalizing left ventricular mass to body surface area (BSA); left ventricular hypertrophy was defined as a LVMI $\geqslant 110 \mathrm{~g} \mathrm{~m}^{-2}$ for women and $\geqslant 125 \mathrm{~g} \mathrm{~m}^{-2}$ for men. ${ }^{16}$ Relative wall thickness (RWT) was calculated using (IVSDd + PWDd)/LVEDd); concentric geometry was present when RWT $>0.45 .{ }^{17}$ LVMI and RWT were used to differentiate four types of left ventricular geometry: normal geometry (RWT $\leqslant 0.45$ and normal LVMI), concentric remodeling (RWT $>0.45$ and normal LVMI), concentric hypertrophy (RWT $>0.45$ and increased LVMI) and eccentric hypertrophy (RWT $\leqslant 0.45$ and increased LVMI) (see Supplementary Figures 1-5).

\section{Statistical Methods}

Collected data was expressed as the mean \pm s.d. and frequency as a percentage. Patients were divided into four groups based on LV geometric type. Significant differences of the studied parameters between the four groups were determined using ANOVA and $X^{2}$-test. Multiple comparisons between the four groups were performed with one-way analysis of variance using the Duncan and Bonferroni post hoc tests. Parameters identified as statistically significant based on univariate analysis $(P<0.05)$ were included in the multivariate logistic regression model in order to determine the combined effect of several variables on the prevalence of the characteristics. All statistical analyses were performed with commercially available computer software: PASW Statistics 18 (SPSS, Chicago, IL, USA). $P<0.05$ was considered statistically significant.

\section{RESULTS}

We analyzed 155 patients (92 males, 63 females, mean age $47.5 \pm 10.5$ years) with true RHTN and without secondary causes of hypertension. Patients were divided into four groups based on the LV geometric patterns (Figure 2): group 1 (normal geometry) $(n=38,24.4 \%)$, group 2 (concentric remodeling) $(n=40,25.8 \%)$, group 3 (eccentric hypertrophy) ( $n=26,16.8 \%)$ and group 4 (concentric hypertrophy) 
( $n=51,33 \%)$. The clinical characteristic of the studied groups is presented in Table 1. MS was found in $64 \%$ and clinically significant OSA in $43.2 \%$ of subjects. In subjects with concentric hypertrophy, the AHI was significantly higher and clinically significant OSA was more frequent compared with patients with normal geometry. Patients in group 4 were older and had higher blood pressure values compared with the other groups. There were no differences in aldosterone serum concentration and 24-h urinary sodium excretion between the four analyzed groups. The median number of antihypertensive drugs was four and individual antihypertensive medication drug classes were prescribed with the following frequencies in the whole group: thiazide/

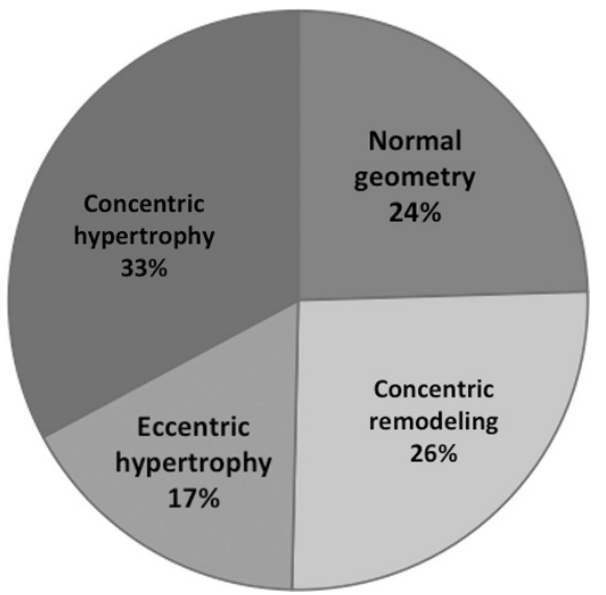

Figure 2 Prevalence of respective type of LV geometry in the study. loop diuretics $97.5 \%$, calcium channel blockers $82.8 \%$, ß-blockers 77.9\%, ACE inhibitors 63.2\%, angiotensin II receptor blockers 55.8\%, alpha-blockers $38.6 \%$, centrally acting drugs $11.6 \%$, spironolactone $8.6 \%$ (no patient was receiving eplerenone). There were no significant differences in the frequency of antihypertensive drugs classes between the analyzed groups. There was no difference in GFR between the analyzed groups. Concentric hypertrophy was the most common type of left ventricular geometry (Figure 1). In a multivariate logistic regression model, factors independently associated with concentric hypertrophy were: age10 (for ten years increase) (OR-1.51; 95\% CI-1.00-2.27; $P<0.04$ ), OSA $>15$ events per hour (OR-2.73; 95\% CI-1.26-5.93; $P=0.01$ ) and nighttime systolic blood pressure (OR-1.69; 95\% CI-1.32-2.17; $P=0.0001$ ) (Table 2).

\section{DISCUSSION}

Patients with RHTN have a significantly increased risk of a cardiovascular event during follow-up compared with patients without RHTN. ${ }^{18}$ This may be related to more pronounced subclinical cardiac damage in patients with RHTN including LV hypertrophy, especially concentric hypertrophy. Abnormal LV geometry including concentric remodeling, eccentric hypertrophy and concentric hypertrophy have been shown to independently predict adverse cardiovascular outcomes in hypertensive populations. Korena et al. ${ }^{4}$ established that patients with concentric hypertrophy had the highest risk of cardiovascular events and death, compared with subjects with normal geometry ( 31 vs $11 \%, P=0.03 ; 21$ vs $0 \% ; P<0.001$ respectively). Patients with eccentric hypertrophy and concentric remodeling were characterized by a higher cardiovascular risk as compared with subjects with normal left ventricle geometry; however, the risk was

Table 1 Baseline characteristics of patients grouped according to type of left ventricular geometry

\begin{tabular}{|c|c|c|c|c|c|}
\hline Variables & $\begin{array}{l}\text { Normal geometry } \\
\text { group } 1(\mathrm{n}=38)\end{array}$ & $\begin{array}{c}\text { Concentric remodeling } \\
\text { group } 2(\mathrm{n}=40)\end{array}$ & $\begin{array}{c}\text { Eccentric hypertrophy } \\
\text { group } 3(n=26)\end{array}$ & $\begin{array}{c}\text { Concentric hypertrophy } \\
\text { group } 4(n=51)\end{array}$ & $\mathrm{P}$ \\
\hline Age (years) & $44.8 \pm 11.0$ & $48.8 \pm 10.8$ & $43.9 \pm 11.7$ & $50.8 \pm 8.2^{\mathrm{a}, \mathrm{b}}$ & 0.009 \\
\hline Gender (M/F) & $21 / 17$ & $26 / 14$ & $15 / 11$ & $30 / 21$ & 0.90 \\
\hline $\mathrm{BMI}\left(\mathrm{kg} \mathrm{m}^{-2}\right)$ & $28.0 \pm 4.7$ & $30.9 \pm 4.7$ & $30.3 \pm 5.6$ & $30.6 \pm 4.4^{a}$ & 0.04 \\
\hline Known history of hypertension (years) & $8.7 \pm 8.7$ & $10.9 \pm 8.3$ & $9.2 \pm 6.5$ & $12.2 \pm 8.9$ & 0.22 \\
\hline Median number of antihypertesive drugs & $4(3-5)$ & $5(3-5)$ & $5(3-6)$ & $5(4-5)^{a}$ & 0.02 \\
\hline GFR $\left(\mathrm{ml} \mathrm{min}-1\right.$ per $\left.1.73 \mathrm{~m}^{2}\right)$ & $90.0 \pm 13.9$ & $90.5 \pm 22.6$ & $92.6 \pm 18.4$ & $91.0 \pm 21.1$ & 0.96 \\
\hline $\mathrm{AHI}$ enents per $\mathrm{h}$ & $12.4 \pm 17.2$ & $25.1 \pm 25.3$ & $17.5 \pm 23.6$ & $26.4 \pm 22.8^{a}$ & 0.02 \\
\hline OSA > 15 events per $h(\%)$ & 18.4 & 53.7 & 20.5 & $79.5^{a, b}$ & $<0.0001$ \\
\hline MS (\%) & 39.5 & 75.6 & 69.2 & $71.2^{\mathrm{a}}$ & 0.003 \\
\hline Microalbuminuria (mg per 24 h) & $11.7 \pm 8.9$ & $23.7 \pm 21.7$ & $15.6 \pm 13.6$ & $22.7 \pm 20.8$ & 0.01 \\
\hline Aldosterone $24-\mathrm{h}$ urine excretion ( $\mu \mathrm{g}$ per $24 \mathrm{~h}$ ) & $16.5 \pm 9.3$ & $21.3 \pm 10.6$ & $20.8 \pm 9.9$ & $20.6 \pm 10.1$ & 0.14 \\
\hline 24-h urinary sodium excretion (mEg per $24 \mathrm{~h}$ ) & $176.6 \pm 75.1$ & $179.9 \pm 88.1$ & $177.4 \pm 69.9$ & $167.6 \pm 76.0$ & 0.89 \\
\hline Office SBP (mmHg) & $148.9 \pm 19.5$ & $159.4 \pm 22.2$ & $154.3 \pm 19.9^{b}$ & $170.7 \pm 20.1^{a}$ & $<0.0001$ \\
\hline Office DBP (mmHg) & $89.5 \pm 10.6$ & $96.8 \pm 13.0$ & $91.9 \pm 16.5^{b}$ & $102.7 \pm 15.0^{\mathrm{a}}$ & $<0.0001$ \\
\hline 24-h SBP (mmHg) & $130.4 \pm 14.4$ & $137.9 \pm 16.3$ & $136.0 \pm 17.2$ & $145.7 \pm 18.2^{a, b}$ & $<0.0001$ \\
\hline 24-h DBP (mmHg) & $79.9 \pm 10.2$ & $85.6 \pm 11.9$ & $83.4 \pm 14.3$ & $89.8 \pm 12.9^{a}$ & 0.003 \\
\hline Daytime SBP (mmHg) & $135.9 \pm 15.0$ & $142.5 \pm 18.3$ & $141.7 \pm 19.3$ & $150.1 \pm 19.2^{\mathrm{a}}$ & 0.004 \\
\hline Daytime DBP (mmHg) & $84.4 \pm 10.6$ & $90.1 \pm 12.2$ & $87.7 \pm 15.5$ & $92.9 \pm 13.5^{\mathrm{a}}$ & 0.02 \\
\hline Nighttime SBP (mmHg) & $119.6 \pm 15.5$ & $128.0 \pm 14.1$ & $125.3 \pm 15.2$ & $137.8 \pm 18.4^{a, b, c}$ & $<0.0001$ \\
\hline Nighttime DBP (mmHg) & $71.3 \pm 10.6$ & $78.2 \pm 10.9$ & $76.4 \pm 12.6$ & $82.5 \pm 11.9^{a}$ & $<0.0001$ \\
\hline 24-h HR (beats $\min ^{-1}$ ) & $67.0 \pm 10.1$ & $69.7 \pm 9.7$ & $65.7 \pm 7.8$ & $70.0 \pm 10.1$ & 0.25 \\
\hline
\end{tabular}

Abbreviations: AHI, apnea/hypopnea index; BMI, body mass index; DBP, diastolic blood pressure; GFR, glomerular filtration rate; HR, heart rate; MS, metabolic syndrome; OSA > 15, clinical important obstructive sleep apnea; SBP, systolic blood pressure.

The results are presented as mean \pm one s.d. or median and interquartile range in the parenthesis. Categorical variables are shown as frequencies.

The variables in bold are statistically significant.

aGroup 4 vs group 1 .

Group 4 vs group 3.

'Group 4 vs group 2. 
Table 2 Univariate and mutivariate analysis showing the relationship between concentric hypertrophy and clinical parameters

\begin{tabular}{|c|c|c|c|c|c|c|}
\hline \multirow[b]{2}{*}{ Variables } & \multicolumn{3}{|c|}{ Univariate model } & \multicolumn{3}{|c|}{ Multivariate model } \\
\hline & $O R$ & $95 \% \mathrm{Cl}$ & $P$ & $O R$ & $95 \% \mathrm{Cl}$ & $P$ \\
\hline Age-10 & 1.61 & $1.12-2.32$ & 0.01 & 1.51 & $1.00-2.27$ & 0.04 \\
\hline Gender & 1.05 & $0.54-2.07$ & 0.87 & & & \\
\hline 24SBP-10 & 1.04 & $1.02-1.06$ & 0.0001 & & NS & \\
\hline 24DBP-10 & 1.04 & $1.02-1.07$ & 0.002 & & NS & \\
\hline Daytime SBP-10 & 1.35 & $1.12-1.64$ & 0.002 & & NS & \\
\hline Daytime DBP-10 & 1.38 & $1.06-1.79$ & 0.02 & & NS & \\
\hline Nighttime SBP-10 & 1.64 & $1.30-2.06$ & 0.0001 & 1.69 & $1.32-2.17$ & 0.0001 \\
\hline Nighttime DBP-10 & 1.69 & $1.24-2.28$ & 0.001 & & NS & \\
\hline MS & 1.58 & $0.78-3.24$ & 0.21 & & & \\
\hline OSA $>15$ & 2.71 & $1.37-5.37$ & 0.004 & 2.73 & $1.26-5.93$ & 0.01 \\
\hline Aldosterone $24-\mathrm{h}$ urine excretion ( $\mu$ g per $24 \mathrm{~h}$ ) & 1.01 & $0.98-1.05$ & 0.44 & & & \\
\hline HR-24 h & 1.02 & 0.99 & 1.06 & & & \\
\hline 24-h urinary sodium excretion & 0.99 & $0.99-1.00$ & 0.48 & & & \\
\hline
\end{tabular}

Abbreviations: $\mathrm{Cl}$, confidence interval; DBP,diastolic blood pressure; HR, heart rate; MS, metabolic syndrome, NS, no statistically significant; OR, odds ratio; OSA > 15, clinical important obstructive sleep apnea; SBP, systolic blood pressure.

The variables in bold are statistically significant.

lower than in patients with concentric hypertrophy. Thus they confirmed that concentric hypertrophy is related to the highest mortality and morbidity compared with other types of left ventricular geometry. Additionally Wang et al. ${ }^{19}$ found that left ventricular concentric hypertrophy is the strongest marker related to stroke risk in patients with hypertension. Our study confirms the very-high prevalence of concentric hypertrophy in patients with RHTN; present in $33 \%$ of subjects.

To our knowledge, there has been little information published concerning factors associated with concentric hypertrophy in patients with RHTN. Hypertension was present in all our patients. The second most common clinical condition was MS; present in 64\% of studied subjects. Clinically significant OSA (AHI > 15 events per hour) was present in $43.2 \%$ of patients. We systematically evaluated which clinical condition might be related to concentric hypertrophy. The important finding of our study is that the presence of clinically significant OSA and higher nocturnal BP are independently associated with concentric hypertrophy in patients with RHTN.

Other researchers have investigated the relationship between OSA and LVH. Koga et al. ${ }^{20}$ evaluated 37 men with OSA and 34 agematched healthy men as controls. Compared with the controls, the OSA patients had a higher prevalence of concentric hypertrophy patterns ( 54 vs $0 \%, P<0.001)$. In a multivariate analysis the authors demonstrated that the apnea-hypopnea index was a significant and independent factor associated with the presence of concentric hypertrophy (OD- $1.06, P=0.008$ ). They also found that 3 months of CPAP treatment resulted in significant decrease in LVMI and also resulted in lower rate of patients with concentric hypertrophy. Cioffi et al. ${ }^{21}$ reported that moderate to severe OSA and higher BMIs are associated with an increased prevalence of concentric hypertrophy in patients with OSA. On the other hand, $\mathrm{Chami}^{22}$ and colleague demonstrated that in patients with OSA the frequency of eccentric hypertrophy is higher than that of concentric hypertrophy. The prevalence of eccentric hypertrophy was associated with a higher AHI. In our study the AHI was not confirmed as an independent factor of concentric hypertrophy.

The relationship between concentric hypertrophy and ambulatory BP levels (in particular nocturnal blood pressure levels) is still a matter of debate. De la Sierra et al. ${ }^{23}$ in the Spanish registry demonstrated that $\mathrm{BP}$ values from ambulatory blood pressure monitoring are independently and significantly associated with cardiovascular event risk in patients with treated hypertension and high or very-high cardiovascular risk. The nighttime systolic BP values had the strongest predictive value in this analysis. For the first time, Redon et al. ${ }^{24}$ evaluated the prognostic importance of ambulatory BP in RHTN. During a mean follow-up period of 4 years, there were 2, 9 and 10 events in the lowest $(\mathrm{BP}<88 \mathrm{~mm} \mathrm{Hg}$ ), middle (BP 88-97 $\mathrm{mm} \mathrm{Hg}$ ), and highest tertile (BP> $97 \mathrm{~mm} \mathrm{Hg})$, respectively. In comparison with patients classified in the lowest tertile, the adjusted relative risk of cardiovascular events was $6.42,95 \%$ CI $1.39-29.7, P<0.02$, in those classified in the highest tertile, and 3.69, 95\% CI 0.79-17.33, $P<0.098$, in those classified in the middle tertile. Thus, subjects with the lowest ambulatory BP had the lowest risk of cardiovascular events. Verdecchia et al. ${ }^{25}$ reported that ambulatory BP monitoring is superior to BP monitoring in the clinic for predicting cardiovascular risk in treated hypertensive patients. In our study, nighttime systolic blood pressure together with clinically significant OSA were significant factors independently associated with concentric hypertrophy. Our finding may suggest that in patients with RHTN, the nocturnal consequences of OSA, including an increased nocturnal systolic pressure because of respiratory effort during an apneic event, hypoxemia and increased sympathetic neural activity, could account for the development of concentric hypertrophy. There is no sufficient data to prove that controlling nighttime systolic BP results in reversing remodeling of concentric LVH.

Suggestions have been made that RHTN may be characterized as a state of hyperaldosteronism. It was shown that higher aldosterone levels might be related to more pronounced left ventricular hypertrophy. In our study we found no relationship between concentric LVH and aldosterone concentration. This might be explained by the fact that the patients with primary hyperaldosteronism were purposely excluded from the study thus limiting the number of patients with higher aldosterone levels. It should be highlighted that in a group of patients with primary hyperaldosteronism and OSA, the presence of OSA was associated with concentric remodeling, but the presence of primary hyperaldosteronism was associated with higher left ventricular mass and higher frequency of left ventricular hypertrophy. ${ }^{26}$ Moreover, studies demonstrating a relationship between aldosterone levels and concentric LVH were based on a larger sample from the general population and the correlation was relatively modest. 
The last important finding of our study is that we have not confirmed that MS is an independent factor of concentric hypertrophy. MS often coexists in patients with RHTN and can also influence LV concentric hypertrophy. Mancia et al. ${ }^{27}$ established a higher prevalence of LVH in patients with MS compared with groups without MS. In this study the most important predictor of newonset LVH was the initial LVMI value with independent contributions from BP, metabolic and body weight alterations. However, the MS was not found to be an independent predictor of new-onset $\mathrm{LVH}$ when included together in the multivariate analysis. The presented results are very similar. In the univariate model, MS was significantly associated with concentric hypertrophy, but in multivariate model this association was not confirmed. On the other hand, Grandi et al. ${ }^{28}$ analyzed 38 patients with and 50 without MS. In the MS group, LVMI and RWT were significantly higher than in the group without MS $(P=0.0015, P=0.0021$ respectively). In this study, the association between the presence of MS and concentric LV geometry was confirmed by using a stepwise multiple regression analysis. In another study, the same group of authors achieved similar results. ${ }^{29}$ In patients with MS, there was a higher prevalence of LV hypertrophy compared with patients without MS (57.7 vs $25.1 \%$; $P<0.00001$ ). The independent relationships between LV mass and MS was confirmed in multivariate regression models including MS together with its individual components. Previous studies demonstrated the relationship between cardiovascular structure and some components of the MS. Lind et al. ${ }^{30}$ found that LVH in the untreated hypertensive group was related to decreased insulin sensitivity, but Horio et al. ${ }^{31}$ reported that HDL cholesterol was inversely associated with left ventricular mass.

The main limitation of this study is a middle aged (or younger) group of patients with preserved renal function and without any history of diabetes, thus mitigating the potential confounding effects of advanced age and comorbidities in our results. Therefore, our results may not be applicable to a wider population of patients with truly RHTN.

\section{CONCLUSION}

Concentric hypertrophy was the most frequent type of left ventricular geometry in patients with RHTN. Nighttime systolic blood pressure and clinically significant OSA levels were independently associated with concentric hypertrophy in patients with RHTN. Our study clearly indicated the relevant association between subclinical left ventricular damage, nighttime BP levels and sleep disturbances.

\section{CONFLICT OF INTEREST}

The authors declare no conflict of interest.

\section{ACKNOWLEDGEMENTS}

The study was supported by the Ministry of Science and Higher Education NN 402190335 .

1 Lorell BH, Carabello BA. Left ventricular hypertrophy: pathogenesis, detection, and prognosis. Circulation 2000; 102: 470-479.

2 Levy D, Garrison RJ, Savage DD, Kannel WB, Castelli WP. Prognostic implications of echocardiographically determined left ventricular mass in the framingham heart study. N Engl J Med 1990; 322: 1561-1566.

3 Verdecchia P, Schillaci G, Borgioni C, Ciucci A, Battistelli M, Bartoccini C, Santucci A, Santucci C, Reboldi G, Porcellati C. Adverse prognostic significance of concentric remodeling of the left ventricle in hypertensive patients with normal left ventricular mass. J Am Coll Cardiol 1995; 25: 871-878.
4 Koren MJ, Devereux RB, Casale PN, Savage DD, Laragh JH. Relation of left ventricular mass and geometry to morbidity and mortality in uncomplicated essential hypertension. Ann Intern Med 1991; 114: 345-352.

5 Acelajado MC, Pisoni R, Dudenbostel T, Dell'Italia LJ, Cartmill F, Zhang B, Cofield SS, Oparil S, Calhoun DA. Refractory hypertension: definition, prevalence, and patient characteristics. J Clin Hypertens (Greenwich) 2012; 14: 7-12.

6 Calhoun DA, Jones D, Textor S, Goff DC, Murphy TP, Toto RD, White A, Cushman WC, White W, Sica D, Ferdinand K, Giles TD, Falkner B, Carey RM. Resistant hypertension: diagnosis, evaluation, and treatment. A scientific statement from the american heart association professional education committee of the council for high blood pressure research. Hypertension 2008; 51: 1403-1419.

7 Kumbhani DJ, Steg PG, Cannon CP, Eagle KA, Smith SC Jr, Crowley K, Goto S, Ohman EM, Bakris GL, Perlstein TS, Kinlay S, Bhatt DL. Resistant hypertension: a frequent and ominous finding among hypertensive patients with atherothrombosis. Eur Heart J 2012; 34: 1204-1214.

8 Muiesan ML, Salvetti M, Rizzoni D, Paini A, Agabiti-Rosei C, Aggiusti C, Agabiti Rosei E. Resistant hypertension and target organ damage. Hypertens Res 2013; 36: 485-491.

9 Parati G, Ochoa JE, Bilo G, Mattaliano P, Salvi P, Kario K, Lombardi C. Obstructive sleep apnea syndrome as a cause of resistant hypertension. Hypertens Res 2014; 37: 601-613.

10 Nishikawa T, Omura M, Saito J, Matsuzawa Y. The possibility of resistant hypertension during the treatment of hypertensive patients. Hypertens Res 2013; 36: 924-929.

11 Florczak E, Prejbisz A, Szwench-Pietrasz E, Sliwinski P, Bielen P, Klisiewicz A, Michalowska I, Warchol E, Januszewicz M, Kala M, Witkowski A, Wiecek A, Narkiewicz K, Somers VK, Januszewicz A. Clinical characteristics of patients with resistant hypertension: The resist-pol study. J Hum Hypertens 2013; 27: 678-685.

12 Elliott P, Andersson B, Arbustini E, Bilinska Z, Cecchi F, Charron P, Dubourg O, Kuhl U, Maisch B, McKenna WJ, Monserrat L, Pankuweit S, Rapezzi C, Seferovic P, Tavazzi L, Keren A. Classification of the cardiomyopathies: a position statement from the european society of cardiology working group on myocardial and pericardial diseases. Eur Heart $J$ 2008; 29: 270-276.

13 Ward Flemons W, Buysse D, Redline S, Pack A, Strohl K, Wheatley J, Young T, Douglas N, Levy P, McNicholas W, Fleetham J, White D, Schmidt-Nowarra W, Carley D, Romaniuk J. Sleep-related breathing disorders in adults: Recommendations for syndrome definition and measurement techniques in clinical research. The report of an american academy of sleep medicine task force. Sleep 1999; 22: 667-689.

14 Lang RM, Bierig M, Devereux RB, Flachskampf FA, Foster E, Pellikka PA, Picard MH, Roman MJ, Seward J, Shanewise JS, Solomon SD, Spencer KT, Sutton MS, Stewart WJ. Chamber Quantification Writing G, American Society of Echocardiography's G, Standards C, European Association of E. Recommendations for chamber quantification: A report from the american society of echocardiography's guidelines and standards committee and the chamber quantification writing group, developed in conjunction with the european association of echocardiography, a branch of the european society of cardiology. J Am Soc Echocardiogr 2005; 18: 1440-1463.

15 Devereux RB, Reichek N. Echocardiographic determination of left ventricular mass in man. Anatomic validation of the method. Circulation 1977; 55: 613-618.

16 European Society of Hypertension-European Society of Cardiology Guidelines C. 2003 European society of hypertension-European society of cardiology guidelines for the management of arterial hypertension. J Hypertens 2003; 21: 1011-1053.

17 Ganau A, Devereux RB, Roman MJ, de Simone G, Pickering TG, Saba PS, Vargiu P, Simongini I, Laragh JH. Patterns of left ventricular hypertrophy and geometric remodeling in essential hypertension. J Am Coll Cardiol 1992; 19: 1550-1558.

18 Daugherty SL, Powers JD, Magid DJ, Tavel HM, Masoudi FA, Margolis KL, O'Connor PJ, Selby JV, Ho PM. Incidence and prognosis of resistant hypertension in hypertensive patients. Circulation 2012; 125: 1635-1642.

19 Wang S, Xue H, Zou Y, Sun K, Fu C, Wang H, Hui R. Left ventricular hypertrophy, abnormal ventricular geometry and relative wall thickness are associated with increased risk of stroke in hypertensive patients among the han chinese. Hypertens Res 2014; 37: 870-874.

20 Koga S, Ikeda S, Nakata T, Yasunaga T, Maemura K. Effects of nasal continuous positive airway pressure on left ventricular concentric hypertrophy in obstructive sleep apnea syndrome. Intern Med 2012; 51: 2863-2868.

21 Cioffi G, Russo TE, Stefenelli C, Selmi A, Furlanello F, Cramariuc D, Gerdts E, de Simone G. Severe obstructive sleep apnea elicits concentric left ventricular geometry. $J$ Hypertens 2010; 28: 1074-1082.

22 Chami HA, Devereux RB, Gottdiener JS, Mehra R, Roman MJ, Benjamin EJ, Gottlieb DJ. Left ventricular morphology and systolic function in sleep-disordered breathing: The sleep heart health study. Circulation 2008; 117: 2599-2607.

23 de la Sierra A, Banegas JR, Segura J, Gorostidi M, Ruilope LMInvestigators CE. Ambulatory blood pressure monitoring and development of cardiovascular events in high-risk patients included in the spanish abpm registry: The cardiorisc event study. $J$ Hypertens 2012; 30: 713-719.

24 Redon J, Campos C, Narciso ML, Rodicio JL, Pascual JM, Ruilope LM. Prognostic value of ambulatory blood pressure monitoring in refractory hypertension: A prospective study. Hypertension 1998; 31: 712-718.

25 Verdecchia P, Porcellati C, Schillaci G, Borgioni C, Ciucci A, Battistelli M, Guerrieri M, Gatteschi C, Zampi I, Santucci A, Santucci C, Reboldi G et al. Ambulatory blood pressure. An independent predictor of prognosis in essential hypertension. Hypertension 1994: 24: 793-801.

26 Prejbisz A, Florczak E, Klisiewicz A, Dobrowolski P, Janaszek-Sitkowska H, Bielen P, Szwench-Pietrasz E, Warchol-Celinska E, Kolodziejczyk-Kruk S, Janas J, Kabat M, 
Imiela J, Sliwinski P, Januszewicz A. Relationship between primary aldosteronism and obstructive sleep apnoea, metabolic abnormalities and cardiac structure in patients with resistant hypertension. Endokrynol Pol 2013; 64: 363-367.

27 Mancia G, Bombelli M, Facchetti R, Madotto F, Corrao G, Trevano FQ, Giannattasio C, Grassi G, Sega R. Long-term risk of diabetes, hypertension and left ventricular hypertrophy associated with the metabolic syndrome in a general population. Hypertens 2008; 26: 1602-1611.

28 Grandi AM, Maresca AM, Giudici E, Laurita E, Marchesi C, Solbiati F, Nicolini E, Guasti L, Venco A. Metabolic syndrome and morphofunctional characteristics of the left ventricle in clinically hypertensive nondiabetic subjects. Am J Hypertens 2006; 19: 199-205.
29 Mule G, Nardi E, Cottone S, Cusimano P, Volpe V, Piazza G, Mongiovi R, Mezzatesta G, Andronico G, Cerasola G. Influence of metabolic syndrome on hypertension-related target organ damage. J Intern Med 2005; 257. 503-513.

30 Lind L, Andersson PE, Andren B, Hanni A, Lithell HO. Left ventricular hypertrophy in hypertension is associated with the insulin resistance metabolic syndrome. $J$ Hypertens 1995; 13: 433-438.

31 Horio T, Miyazato J, Kamide K, Takiuchi S, Kawano Y. Influence of low high-density lipoprotein cholesterol on left ventricular hypertrophy and diastolic function in essential hypertension. Am J Hypertens 2003; 16: 938-944.

Supplementary Information accompanies the paper on Hypertension Research website (http://www.nature.com/hr) 